\title{
Modeling and Numerical Simulation of a Buoyancy Controlled Ocean Current Turbine
}

\author{
Arezoo Hasankhani, James VanZwieten, Yufei Tang, Broc Dunlap, Alexandra De Luera, Cornel \\ Sultan, and Nikolaos Xiros
}

\begin{abstract}
Increased global renewable power demands and the high energy density of ocean currents have motivated the development of ocean current turbines (OCTs). Compliant mooring systems will be used together with variable buoyancy, lifting surface, sub-sea winches, and/or surface buoys to maintain desired near-surface operating depths. This paper presents a complete numerical simulation of a $700 \mathrm{~kW}$ variable buoyancy controlled OCT that includes a detailed turbine system, inflow, actuator (i.e., generator and variable buoyancy), sensor, and fault models. Simulation predictions of OCT performance are made for normal, hurricane, and fault scenarios. Results suggest this OCT can operate between depths of $38 \mathrm{~m}$ to $90 \mathrm{~m}$ for all homogeneous flow speeds between 0.5$2.5 \mathrm{~m} / \mathrm{s}$. Fault scenarios show that rotor braking faults will result in a rapid vertical OCT system assent and blade pitch faults will create power fluctuations apparent in the frequency domain. Finally, the OCT power statistics and system behaviors are quantified under typical and extreme operations using measured ocean currents with normal and hurricane conditions.
\end{abstract}

Index Terms-Renewable Energy, Ocean Current Turbines, Numerical Simulation, Fault-Tolerant Control, Variable Buoyancy.

\section{INTRODUCTION}

E LECTRICITY production from renewable energy sources has been steadily increasing due to environmental concerns associated with fossil fuels and recent advances in enabling technologies. This growth includes the increasing installation of both solar and wind technologies, as well as a push to harness additional renewable energy resources, such as marine renewable energy. Although marine renewable energy technologies are still in their infancy when compared

Manuscript received 15 November, 2020; revised 28 May, 2021; accepted 2 July, 2021; published 31 July, 2021. This is an open access article distributed under the terms of the Creative Commons Attribution 4.0 licence (CC BY http://creativecommons.org/licenses/by/4.0/). Unrestricted use (including commercial), distribution and reproduction is permitted provided that credit is given to the original author(s) of the work including a URI or hyperlink to the work, this public license and a copyright notice. This article has been subject to single-blind peer review by a minimum of two reviewers.

This work was supported in part by the National Science Foundation under Grant Nos. ECCS-1809164/1809404/1809182 and the US Department of Energy under Grant No. DE-EE0008955.

A. Hasankhani, J. VanZwieten, Y. Tang, B. Dunlap, and A. De Luera are with Florida Atlantic University, Boca Raton, FL 33431, USA (e-mails: ahasankhani2019@fau.edu, jvanzwi@fau.edu, tangy@fau.edu, bdunlap2013@fau.edu, adeluera2014@fau.edu).

Cornel Sultan is with Virginia Tech, 460 Old Turner St., Blacksburg, VA 24061, USA (e-mail: csultan@vt.edu).

Nikolaos Xiros is with University of New Orleans, 2000 Lakeshore Dr., New Orleans, LA 70148, USA (e-mail: nxiros@uno.edu).

Digital Object Identifier: https://doi.org/10.36688/imej.4.47-58 to other types of renewable energies, their vast power production potential along with the success of numerous prototype testing campaigns have encouraged the transition of these technologies into array deployments and interconnection with the electrical grid. A recent study suggests that about $2000 \mathrm{GW}$ of power can be extracted from waves globally (300 GW from U.S. waters) and $1000 \mathrm{GW}$ from tidal currents globally (50 GW in U.S.) [1]. In the U.S., an additional $14 \mathrm{GW}$ of instream hydrokinetic power (i.e., not using dams) can be extracted from rivers [2] and 18.6 GW can be extracted from offshore ocean currents [3].

Significant potential for ocean current energy extraction exists along the western boundaries of ocean basins [4]. The Gulf Stream contains roughly 18.6 GW (i.e., $163 \mathrm{TWh} /$ year) of available power in U.S. waters between Southeast Florida and North Carolina, with the Florida Current portion of the Gulf Stream containing 5.1 GW (i.e., $45 \mathrm{TWh} /$ year) [3], [5]. While similar energy estimates are not readily available for other targeted ocean current resources, these Gulf Stream estimates and other related flow statistics suggest that other currents also contain major renewable energy resources. For example, the Gulf Stream carries 31 million $\mathrm{m}^{3} / \mathrm{s}$ of water to the North Atlantic ocean [6], while the Kurishio current transports 30-50 million $\mathrm{m}^{3} / \mathrm{s}$ of water (reported from 6 measurement campaigns from 1970-1972) [7]. Additionally, the east coast of South Africa is bound by the Agulhas Current, which flows southbound as a fast and narrow stream transporting an average of 70 million $\mathrm{m}^{3} / \mathrm{s}$ (reported for a 267-day period) $[8]$.

Ocean currents not only posses large quantities of extractable power, but are also very power dense in several areas. This power density is depth dependent, with the highest values near the sea surface [9]. The near surface maximum power densities off Japan and South Africa at a depth of $20 \mathrm{~m}$ are estimated to be 2.15 $\mathrm{kW} /$ mathrmm $^{2}$ and $2.17 \mathrm{~kW} /$ mathrmm ${ }^{2}$, respectively [10], while the time averaged power density off the southeast coast of the U.S. reaches $3.0 \mathrm{~kW} /$ mathrmm $^{2}$ at a depth of $50 \mathrm{~m}$ [9]. Compliant mooring systems must be used, since large ocean currents are strongest near the surface and are typically located where total water depths range from hundreds to thousands of meters [4]. To locate moored Marine Current Turbines (including river, tidal, and ocean current turbines) near the sea-surface where the current is strongest, yet below the sea surface to avoid surface effects and/or interactions with surface vessels, several systems have been proposed to maintain a proper operating depth: 
variable buoyancy [11]-[15], lifting surfaces or wings [16]-[20], sub-sea winches [21], and surface buoys [22], [23]. In this article, we will focus on simulating a variable buoyancy solution, as this design type was the first to be deployed in an open ocean current while moored directly to the sea floor [11].

Several variable buoyancy turbine designs have been proposed. The system developed and tested by the University of Naples [12] has counter-rotating propellers, variable buoyancy control, a unique v-tail configuration, and was designed to generate the rated power of $100 \mathrm{~kW}$ at flow speeds of $2.8 \mathrm{~m} / \mathrm{s}$. A buoyancy controlled turbine with a rated power of $1.2 \mathrm{MW}$ was proposed in [13]. The air compressor proposed for this system was designed to pump air, or another working fluid, in order to provide appropriate pressure. Recently, a 1/5th scale turbine named Floating Kuroshio Turbine (FKT) is being designed with the proposed corresponding full scale system of $20 \mathrm{~kW}$ at $1.5 \mathrm{~m} / \mathrm{s}$ [14], [15]. This proposed FKT turbine includes two rotors and a foil float with two aft- and two forebuoyancy engines, so the float (i.e., buoyancy engine) is responsible for providing variable buoyancy.

The technical design and in-water testing of moored OCT systems has been conducted by both industry and academia. The first on-site prototype testing for turbines designed to operate in deep water offshore currents was the Vertical Axis Hydro Turbine, which was developed by Nova Energy Limited and the National Research Council of Canada [24], [25]. This OCT was successfully tested from an anchored vessel in the Gulf Stream during a one-day mission in April, 1985. Aquantis spent nearly a decade developing variants of its 2.5 MW C-plane, dual-rotor turbine designed to extract energy from the Gulf Stream [16], with two separate moored prototype tests conducted in towing tanks [26], [27]. Anadarko successfully tested their OCT system in the Gulf of Mexico, producing approximately $12 \mathrm{~kW}$ of shaft power with a $1 / 5$ th scale system [28]. This proposed system uses an induction generator with fin-ring propellers. In 2017, IHI Corporation began testing an OCT in the Kuroshio current off Japan that uses a dual-rotor, $100 \mathrm{~kW}$ turbine system to capture kinetic energy [11], [29].

In 2020, three different OCTs were tested in Gulf Stream during a multi-day mission designed to verify the capability of producing electricity over a 24 hour period [30]. In addition, National Taiwan University built an $800 \mathrm{~W}$ (1/5th scale) test apparatus model placed in a towing tank, which was also successfully tested in the open water of the Kuroshio Current [31]. This test quantified the hydrodynamic performance by establishing values for the rotor rotation speed, torque, and thrust. Further, National Taiwan University did a towing test on a $1 / 25$ th scale FKT turbine at the towing tank to quantify the torque, power, and thrust coefficients [14]. Another towing test was done in Kuroshio currents, while the $1 \mathrm{~kW}$ turbine was attached to a small boat and towed to simulate the ocean currents [23]. In addition, the next phase of testing on the designed turbine was done to find both the operation of the mooring system and impacts of waves on the turbine, which was tested at a circulating water channel (length $=48 \mathrm{~m}$, width $=4 \mathrm{~m}$, and depth $=1.67 \mathrm{~m}$ ) using the wave-making facilities with the flow speed of $2 \mathrm{~m} / \mathrm{s}$, and the maximum wave height of $0.3 \mathrm{~m}$ [32].

Numerical simulations of moored turbines have also been developed, along with control system technologies. A pitch controller was designed for harnessing constant power while minimizing thrust of OCT system [33], [34]. Numerical tools have been developed and evaluated for single- and dual-rotor OCTs with mooring cables that are designed for operation in the deep waters of the Gulf Stream [35]. The motion of the OCT system has also been simulated considering real conditions [36] and controlled using pitch control [37] by the University of Tokyo. Moreover, the dynamic motion of a floating type OCT (i.e., contra-rotating OCT) and a twin-rotor type OCT have been simulated [38], where the numerical model of the twin-rotor type OCT has been described using 6-DOF [39] and its transient movement [40], as well as the movement during rotor rotation initiation and during system failures [41]. The numerical simulation of the OCT system has been addressed in [42], [43] without considering any feedback or fault in their OCT model. In addition, the numerical model of an OCT system using winglike surfaces [26] and blade pitch control [44] has been preliminarily explored.

One of the main challenges of developing ocean energy is the high investment costs, especially for operation and maintenance (O\&M), which can be reduced through fault-tolerant control and conditionbased maintenance. A control benchmark has been proposed for detecting faults and designing the fault tolerant control for OCT system [45]. Deep bidirectional long short-term memory networks [46], empirical mode decomposition techniques [47], continuous wavelet transform [48], [49], and sparse autoencoder and softmax regression method [50] have been proposed for OCT fault detection. Moreover, the prognostic health management and predicting remaining useful life of OCT system have been investigated in [51], [52]. However, the faults, sensor error, actuator error, fault detection, and machine health prognostic are still minimally studied in the field of OCT systems.

The rest of this article is organized as follows. Section III presents the simulated OCT system design, previously developed numerical simulation algorithms used in this project, inflow modeling, sensor modeling, and actuator modeling. Section III introduces the modeling of blade, actuator, and sensor faults that are most likely to occur in OCTs. Section IV predicts the performance of an OCT under different operating and fault conditions. Finally, Section $\mathrm{V}$ presents the conclusions of this article.

\section{Ocean Current Turbine Modeling}

The developed high-fidelity numerical simulation platform has many similarities to the $700 \mathrm{~kW}$, 3-blade horizontal axis OCT turbine design from [44], which also has many geometric and inertial characteristics 


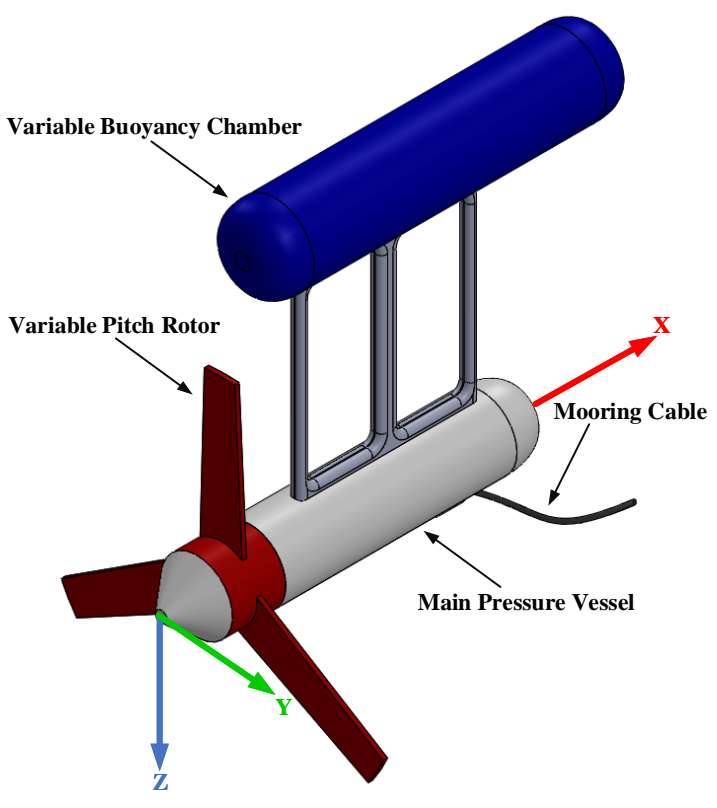

Fig. 1. Schematic of the numerically simulated buoyancy controlled ocean current turbine.

scaled from a $20 \mathrm{~kW}$ experimental OCT located at Southeast National Marine Renewable Energy Center (SNMREC) [53], [54]. In this section, we detail the numerically modeled OCT specifications, provide an overview of previously published numerical simulation algorithms used in this study, and present new simulation advancements. These new modeling advancements include environmental models that utilize ocean current measurements, actuator models, and sensor models.

\section{A. Overview of the Modeled and Simulated OCT}

The investigated OCT system is a representative design with the basic features necessary for operation in the Gulf Stream current off Florida's East Coast. The designed $700 \mathrm{~kW}$ system has a single $20 \mathrm{~m}$ diameter variable pitch rotor, which is described in detail in [44]. Its geometric and inertial parameters are set to those in [44| which are scaled from the $20 \mathrm{~kW}$ turbine presented in [42], besides those of the variable buoyancy chamber which replaces the "buoyancy compensation modules" in previous nearly neutrally buoyant designs.

The dimensions of this OCT are presented here, with all locations and moments of inertia referenced to the center of rotation of the rotor (i.e., coaxial with the rotor shaft) at its front surface. Provided moments of inertia values for the entire OCT assume the variable buoyancy tanks are empty (i.e., do not contain water) and are $I_{x x}=1.35 \times 10^{7} \mathrm{kgm}^{3}, I_{y y}=4.74 \times 10^{7} \mathrm{kgm}^{3}$, and $I_{z z}=3.45 \times 10^{7} \mathrm{kgm}^{3}$. Moreover, the total mass is $4.98 \times 10^{5} \mathrm{~kg}$ without considering ballast water. The variable buoyancy chamber is divided internally into two separate buoyancy tanks, each with $3.20 \times 10^{4} \mathrm{~kg}$ $\left(31.251 \mathrm{~m}^{3}\right)$ of variable ballast. These ballast tanks were sized such that the OCT achieves an operating depth near $50 \mathrm{~m}(50.4 \mathrm{~m})$ when each ballast tank is half filled with water in a homogeneous current speed of $1.6 \mathrm{~m} / \mathrm{s}$.

The center of the collective fixed and variable ballast tank (i.e., the variable buoyancy chamber) is located at $x=9.58 \mathrm{~m}, y=0 \mathrm{~m}$, and $z=-15.34 \mathrm{~m}$, and it has an overall length of $20.00 \mathrm{~m}$ and a diameter of $4.45 \mathrm{~m}$. This OCT is $90 \mathrm{kN}$ positively buoyant when the ballast tanks are filled with water and $718 \mathrm{kN}$ when they are filled with air. The main pressure vessel that houses the generator, gearbox, and electronics is aligned with the rotor and has a length and diameter of $14.76 \mathrm{~m}$ and $3.98 \mathrm{~m}$ respectively. In addition, the single $607 \mathrm{~m}$ long mooring cable has a diameter of $0.16 \mathrm{~m}$, slightly smaller than the $0.20 \mathrm{~m}$ diameter double-armor umbilical suggested for a $5 \mathrm{MW}$ offshore wind turbine [55]. The resulting displaced mass of this cable based on its geometry is $20.6 \mathrm{~kg} / \mathrm{m}$, and a mass of $46 \mathrm{~kg} / m$ is assumed based on the average density of a double-armor umbilical suggested for offshore wind in [55]. This cable is attached to the OCT at the location $x=11.85 \mathrm{~m}, y=0 \mathrm{~m}$, and $z=3.00 \mathrm{~m}$ so that a near zero pitch angle is achieved (1.1 deg) when both buoyancy tanks are half filled with water in a homogeneous flow speed of $1.6 \mathrm{~m} / \mathrm{s}$. A representative sketch of this system is provided in Fig. 1 to show the relative scale and location of the primary OCT components.

\section{B. Previously Developed OCT Simulation Algorithms}

The numerical modeling of OCT systems was addressed in a series of publications focused on system dynamics and environmental conditions. The initial mathematical modeling approach was used to describe the dynamics of a nearly neutrally buoyant $20-\mathrm{kW}$ OCT, where the mooring cable was not attached to the sea floor but instead was assumed to be a part of a larger mooring system [42]. The study used a 7 degree of freedom model to assess both linear and angular displacements of the OCT, in addition to the states associated with the cable model. Furthermore, the model considered kinematics, equations of motion, hydrostatics, rotor forces, streamline body forces, cable force, and included a wave model. The hydrodynamic loads on this 3-meter diameter rotor blade were calculated using a blade element momentum approach with a dynamic wake inflow model, using 3D lift and drag coefficients. These 3D lift and drag coefficients were calculated using Xfoil [56] then AirfoilPrep [57] based on the hydrofoil shapes of a rotor blade. Wave effects on calculated turbine forces were based on the wave induced orbital water velocities. The utilized wave spectrum was defined as the product of a Pierson-Moskowitz frequency spectrum and a directional spreading function. Each element of a mooring cable was modeled as a linear element with forces determined by velocity and position of its end nodes using finite element lumped mass approach. Cable forces were calculated considering buoyancy, hydrodynamic drag, gravity, and internal strain.

The same modeling process was enhanced to simulate a $700 \mathrm{~kW}$ OCT to develop the use of variable blade pitch control for regulating position and attitude [44]. Airfoil shapes for the new rotor blade were selected using HARP-Opt, and FX-83-W airfoils were found as the best design for this OCT based on power production 
when compared with numerous other airfoil shapes. On the other hand, all of the lengths, areas, volumes \& masses, and moments of inertia are multiplied by $20 / 3,(20 / 3)^{2},(20 / 3)^{3}$, and $(20 / 3)^{5}$ compared to numbers presented in [42]. In addition, effects of variable blade pitch are simulated, i.e., effects of the individual blade root angles are considered in the angle of attack calculations and when determining the reduced flow rate [44]. Hence, the momentum portion of the blade element model determines the blade root angle according to the last rotor blade to pass its location. In addition, the open- and closed-loop flight controller is applied to move this OCT, which operates according to harmonic oscillations of blade root angles [44] [58].

The turbulence model used in this paper was originally presented in [59]. This model calculates turbulent flow perturbations in time domain, so the free-stream water velocity at each node where hydrodynamic forces are calculated is formulated as the sum of current induced velocity, wave induced velocity, and turbulence induced velocity. This approach is accounted for the temporal, spatial, and directional correlations of turbulence over all numerically modeled components.

\section{Inflow Modeling}

Realistic environmental characterization is important for accurately simulating OCT operation. This includes accurately representing both temporal and spatial variations in the flow field caused by turbulence, waves, and lower frequency flow structures. Wave [42] and turbulence [59] models used in this study were previously described in detail. Here, we describe how this turbulence model is utilized with measured ADCP data to more accurately describe a realistic current environment, including events such as hurricanes. This is important as temporal and three dimensional spatial flow field correlations significantly impact OCT response, and therefore flow induced signals found in generated electrical power can mask fault signatures.

Measured ADCP data previously used in the ocean current resource assessment presented in [60] are integrated into this inflow model. Data used to generate the results presented in this paper were recorded between September 7, 2017 and November 3, 2017 at a latitude of $26.094^{\circ} \mathrm{N}$ and longitude of $-79.800^{\circ} \mathrm{E}$. These data include effects from Hurricane Irma, which struck the Florida Keys on September 10, 2017 [60] before moving up the West Coast of Florida. These data include an unusually high northward current velocity on September $11^{\text {th }}$ and an unusually low northward current velocity on September $26^{\text {th }}$, both of which are likely related to hurricane Irma impacts [60].

ADCP data were first filtered to remove "bad" data using the approach presented in [9]. Here, "bad" data are defined based on ADCP measured "correlation", "percent good", and "echo intensity" spikes that indicate the initial return of side lobe acoustics reflecting from the sea surface. These filtering techniques removed most of the data within the top $50 \mathrm{~m}$ and therefore results above this depth no longer contain information on the actual vertical and other features

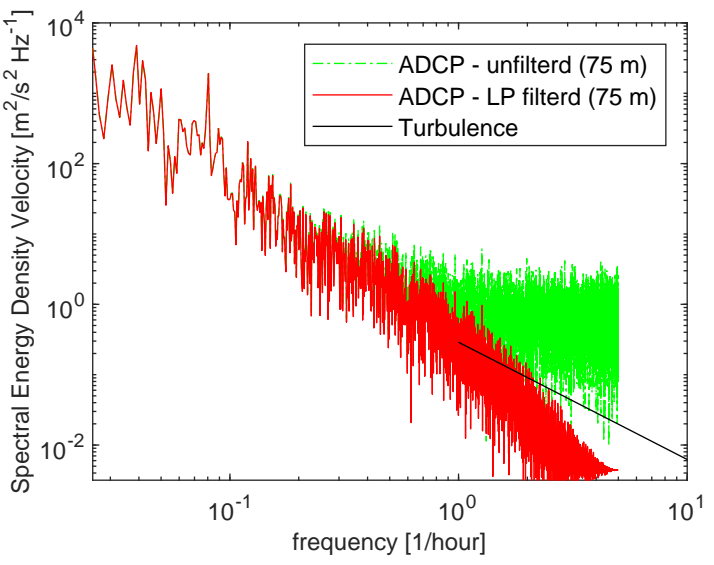

Fig. 2. Northward water velocity spectra for ADCP data at a depth of $75 \mathrm{~m}$ both before and after low pass filtering these data at 1-hour intervals, as well as the spectrum used by turbulence generator.

present in the flow field. Then, to provide flow data estimates throughout the entire water column the "good" data point nearest the surface is used for all elevations above this depth.

The PSD of these ADCP data for a depth of $75 \mathrm{~m}$ flattens at a period of around 1-hour due to Doppler noise (Fig. 2). Therefore, these data are low-pass filtered at a period of 1-hour to minimize Doppler noise, with the resulting spectrum also shown in Fig. 2 and the resulting filtered $\mathrm{ADCP}$ data used in this paper shown in Fig. 3. A turbulence spectrum that follows a $f^{-5 / 3}$ decay is also shown in Fig. 2 with an associated turbulence intensity of $37 \%$ for a frequency range from $1 /(1-$ hour) to $1 /(0.1$-second). It is noted that this spectrum is equivalent to a turbulence intensity of $20 \%$ over the more typical frequency range used for tidal energy applications from $1 /(10$-minutes) to $1 /(0.1$-second) [61]. The utilized turbulence model from [59] is therefore utilized with a frequency range from $1 /(0.1$ second) to $1 /$ (1-hour) and an associated turbulence intensity $37 \%$, which assumes an $f^{-5 / 3}$ decay over this range. This allowed for a smooth transition between the ADCP measurement based flow data and turbulence model calculated flow variations.

\section{Actuator Modeling}

This section presents the actuator models, including the generator model and variable buoyancy model.

Generator Model: The model used to describe the dynamics of the generator in the OCT is given by [62], [63]:

$$
\left\{\begin{array}{c}
\tau_{e m}(s) / \tau(s)=\alpha /(s+\alpha) \\
P_{\text {gen }}(t)=\eta \omega(t) \tau_{\text {em }}(t)
\end{array}\right.
$$

where $\tau_{e m}$ is the electromagnetic torque of the generator, $\alpha$ determines the capacity of the generator, $P_{\text {gen }}$ denotes the generator power, $\omega$ is the rotational speed of generator, and $\eta$ denotes the efficiency of the generator. For this simulation $\alpha=700$ for the $700 \mathrm{~kW}$ OCT and $\eta=0.98$.

Variable Buoyancy Model: The variable buoyancy system has two separate variable buoyancy tanks. Each 


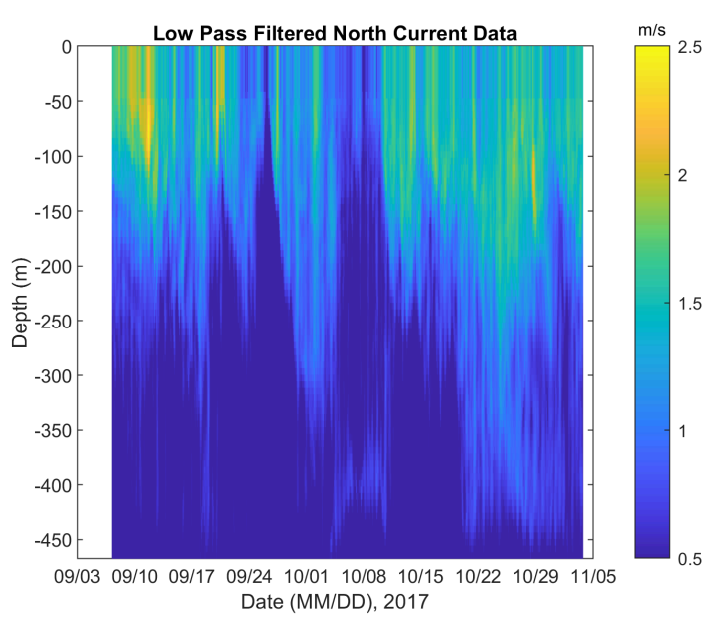

Fig. 3. Northward component of current velocity recorded by a $75 \mathrm{kHz}$ ADCP after filtering out "bad" data, extrapolating data vertically, and low pass filtering these data at 1-hour intervals.

tank can hold $31.251 \mathrm{~m}^{3}$ of air/water, and is sufficiently baffled such that the center of mass of ballast in each tank is not dependent on the orientation of the OCT. This system model is developed to predict ballast pump power usage and to provide reasonable limits on the rate at which water can be transferred into or out of these tanks.

This model assumes that a pump drives water through an opening such that the pressure in the tank is at vacuum pressure (i.e., $P_{a b s} \cong 0 k P a$ ). Using this approach very little power is used (i.e., $P_{\text {fill }} \cong 0$ ) when the tanks are being filled with water, since this can be driven by the natural pressure difference between ambient pressure and vacuum pressure. The power required to pump sea water out of the tank can be calculated using pressure, volumetric flow rate, $Q_{B}$, and pump efficiency:

$$
\begin{gathered}
P_{B}^{\text {fill }}=0 \\
P_{B}^{\text {empty }}=\frac{P \cdot Q_{B}}{\eta_{\text {pump }}}
\end{gathered}
$$

where $\eta_{\text {pump }}=0.75$ is the pump efficiency, $P=P_{a t m}+$ $P_{H S}$. Assuming $P_{a t m}$ is atmospheric pressure $(101 \mathrm{kPa})$ and $P_{H S}$ is hydrostatic pressure $\left(P_{H S}=\rho . g . z\right)$ in $k P a$, where $g=9.81 \mathrm{~m} / \mathrm{s}^{2}$ is gravity. $P_{B}^{\text {empty }}$ in $\mathrm{kW}$ can be rewritten as:

$$
P_{B}^{e m p t y}=\frac{(101+10.1 z) Q_{B}}{0.75}
$$

To find reasonable limits for the volumetric flow rates of water as a function of depth this can be rewritten as:

$$
Q_{B}=\frac{0.75 P_{B}^{e m p t y}}{101+10.1 z}
$$

Assuming a ballast pump power for each ballast tank that is equal to that of WWII era submarines [64] of $P_{B}^{e m p t y}=18.8 \mathrm{~kW}$, a volumetric flow rate $Q_{B}$ of $0.023 \mathrm{~m}^{3} / \mathrm{s}$ is achieved at a depth of $50 \mathrm{~m}$. Since each of the two ballast tanks has a volume of $31.251 \mathrm{~m}^{3}$, these tanks can be completely emptied in 22.2 minutes at this depth, with a total energy usage of $14.02 \mathrm{kWh}$ that is independent of the fill rate.

\section{E. Sensor Modeling}

Sensor models are utilized that set sampling rates while adding synthetic errors to simulation outputs creating realistic feedback and recorded data sets. Sensor parameters are set according to measured sensor performance, manufacturer specifications, and previous studies [45], [65]. Models are specified for IMU (accelerometers, rate gyros, and Euler angles), generator speed, shaft torque, pitch angle, water velocity, rotor speed, and electric power sensors. For all sensor models, besides the IMU model, discrete update rates are directly applied to calculated simulation values, then wide-band random noise components are summed with this signal using values provided in Table I. However, IMU sensor models require additional calculations.

For the IMU model, numerical simulation calculated states at the body fixed frame's origin are first sampled at rates specified in Table I. Gyro measured rotation rates and accelerometer measured accelerations are found using rotation rates and accelerations calculated in the IMU sensor frame summed with sensor bias and noise, producing the following synthesized measurement values:

$$
\begin{gathered}
\omega_{M}=L_{M-B} \omega+c_{\omega}+w_{\omega} \\
a_{M}=L_{M-B}\left(a+\dot{\omega} \times r_{M}+\omega^{2} \times r_{M}\right)+w_{a}
\end{gathered}
$$

where $\omega$ is the rotational velocity vector, $a$ is the acceleration vector, $r_{M}$ is the rotational radius of the IMU measurements in the body fixed frame, $M$ represents synthesized measurements in the IMU measurement frame, $L_{M-B}$ is the body fixed frame to measurement frame transformation matrix based on IMU alignment with the body fixed coordinate system, $w_{\omega}$ and $w_{a}$ are the wide-band noise vectors from Table II and $c_{\omega}=\left[\begin{array}{lll}0.0027 & 0.0041 & 0.0054\end{array}\right]^{T}$ is the rate gyro bias in $\mathrm{rad} / \mathrm{s}$ suggested by [65].

Euler angle outputs from the numerically modeled IMU are found using a Kalman filter that merges 3D gyroscope, accelerometer, and magnetometer data. Hence, constant biases are removed. Therefore, to estimate Euler angle errors, it was suggested by [65 that numerically modeled rate gyro errors can be converted to Euler angle rate errors, integrated, and high-pass filtered before being added to the calculated Euler angles, instead of simply injecting noise into calculated attitude states. IMU measured Euler angles, $\beta_{I M U}$, are not directly calculated from the numerical simulation because the IMU is not required to be co-axial with the body fixed frame. Therefore, this can be calculated using the product transformation matrix from the body to the inertial coordinate system, $L_{I-B}$, and the transformation matrix from the measurement to body coordinate system, $L_{B-M} ; L_{I-M}=L_{I-B} L_{B-M}$ according to:

$$
\beta_{I M U}=\left[\begin{array}{c}
\tan ^{-1}\left(\frac{L_{I-M}(1,2)}{L_{I-M}(1,1)}\right) \\
\sin ^{-1}\left(L_{I-M}(1,3)\right) \\
\tan ^{-1}\left(\frac{L_{I-M}(3,2)}{L_{I-M}(3,3)}\right)
\end{array}\right]
$$


TABLE I

SENSOR CHARACTERISTICS FOR SIMULATED OCT.

\begin{tabular}{c|c|c|c}
\hline Sensor Type & Unit & Noise Power & Rate $(\mathrm{Hz})$ \\
\hline \hline Flow Speed $[\mathrm{u}, \mathrm{v}, \mathrm{w}]$ & $\mathrm{m} / \mathrm{s}$ & {$[1.7 / 1.7 / 5.2] e^{-2}$} & 1.0 \\
\hline Rotor Speed & $\mathrm{rad} / \mathrm{s}$ & $1 e^{-4}$ & 120 \\
\hline Generator Speed & $\mathrm{rad} / \mathrm{s}$ & $2 e^{-4}$ & 120 \\
\hline Generator Torque & $\mathrm{Nm}$ & $9 e^{-1}$ & 120 \\
\hline Pitch Angle & $\mathrm{deg} /{ }^{\circ}$ & $1.5 e^{-3}$ & 120 \\
\hline Power & $\mathrm{Watt}$ & $1 e^{+1}$ & 120 \\
\hline IMU Acceleration $(\mathrm{x} / \mathrm{y} / \mathrm{z})$ & $\mathrm{m} / \mathrm{s}^{2}$ & $w_{a}=[8.1 / 8.5 / 8.5] e^{-3}$ & 100 \\
\hline IMU Rot. Vel. $(\mathrm{x} / \mathrm{y} / \mathrm{z})$ & $\mathrm{rad} / \mathrm{s}$ & $w_{\omega}=[5.5 / 6.0 / 5.1] e^{-3}$ & 100 \\
\hline IMU Euler Ang $(\phi / \theta / \psi)$ & $\mathrm{rad}$ & $\mathrm{NA}$ & 100 \\
\hline & \multicolumn{2}{|r}{}
\end{tabular}

where the numbers in the circle brackets indicate the utilized transformation matrix components.

Error is then added to the Euler angles of the IMU measurements according to:

$$
\beta_{M}=\beta_{I M U}+F_{H P}\left(J_{M} w_{\omega}\right)
$$

where $J_{M}$ is the transformation matrix from rotation rate errors (see Table I) in the IMU measurement frame to the IMU Euler angle rates errors and $F_{H P}$ indicates that variables are High Pass filtered at periods of 600s (roll), 600s (pitch), and 789s (heading) as suggested by [65].

\section{FAULT DESCRIPTION}

This section describes the faults that have been integrated into our OCT simulation. These potential OCT faults are similar to those seen in other renewable energy sectors, such as tidal and wind energy devices. According to [66], the three main fault types that occur in direct drive wind turbines are controller, generator, and rotor faults. Developing and integrating advanced control systems for testing a controller is a future effort and will be left out of this discussion. Therefore, focus areas are (i) rotor faults, (ii) actuator (including generator) faults, and (iii) sensor faults.

\section{A. Rotor Faults}

Rotor faults are likely to occur in the blades due to either a pitch (hydrodynamic) offset [46], [48], [52], hydrofoil performance degradation, or mass imbalance, resulting in the dynamic asymmetry and vibrations of the rotor shaft. For a blade pitch offset fault, the blade pitch angle of one blade, $\beta_{e}$, is offset from the other blades by $\beta_{i}$ :

$$
\beta_{e}=\beta_{\text {ref }}-\beta_{i}
$$

where the desired pitch angle of all blades is $\beta_{\text {ref }}$. To simulate a blade pitch offset fault an error angle, $\beta_{e}$, is used to replace the default angle.

Hydrofoil performance degradation can occur when one section of a blade is damaged due to fatigue, debris, or an extreme load. An example of this is delamination from the lack of cohesion between composite layers that negatively affect the aerodynamic properties of a rotor blade [67]. This fault is modeled by changing the lift $\left(C_{L}^{i}\right)$ and drag $\left(C_{D}^{i}\right)$ coefficients along a section $\left(\bullet^{i}\right)$ of a rotor blade, which affects the calculated values of the axial $\left(C_{A}^{i}\right)$ and tangential $\left(C_{A}^{i}\right)$ force coefficients:

$$
\begin{aligned}
& C_{A}^{i}=C_{L}^{i} \cos \left(\varphi^{i}\right)+C_{D}^{i} \sin \left(\varphi^{i}\right) \\
& C_{T}^{i}=C_{L}^{i} \sin \left(\varphi^{i}\right)+C_{D}^{i} \cos \left(\varphi^{i}\right)
\end{aligned}
$$

where $\varphi^{i}$ is the relative flow angle to the rotor. This induces dynamic axial $\left(f_{A}^{i}\right)$ and tangential $\left(f_{T}^{i}\right)$ loadings on a section of the blade as a function of the respective water velocities $\vec{V}$ :

$$
\begin{aligned}
f_{A}^{i} & =\frac{1}{2} \rho \delta r^{i} c^{i} C_{A}^{i}\left(\left(\vec{V}_{A}^{i}\right)^{2}+\left(\vec{V}_{T}^{i}\right)^{2}\right) \\
f_{T}^{i} & =\frac{1}{2} \rho \delta r^{i} c^{i} C_{T}^{i}\left(\left(\vec{V}_{A}^{i}\right)^{2}+\left(\vec{V}_{T}^{i}\right)^{2}\right)
\end{aligned}
$$

where $\rho$ is the density of seawater, $\delta r^{i}$ is the radial length of a section, and $c^{i}$ is the chord length of a section.

Mass imbalances arise due to a difference in the mass of a single rotor blade from the other blades, with potential causes, including manufacturing defects, bio-fouling, and water intrusion. This fault creates an additional gravitational force, $F_{g}^{p}$, in the inertial frame of reference at the location of the fault that rotates with the blade and an imbalance in the centripetal forces, $f_{c}^{p}$, in the body fixed frame associated with rotor rotation. The forces are modeled as follows:

$$
\left\{\begin{array}{c}
F_{g}^{p}=m^{p} g \\
f_{c}^{p}=m^{p} \omega_{r}^{2} r^{p}
\end{array}\right.
$$

where $\mathrm{g}$ is gravity, $\omega_{r}$ is the rotor rotational speed in $\mathrm{rad} / \mathrm{s}, m^{p}$ is the additional mass added to the rotor blade, and $r^{p}$ is the radial location of this additional mass.

\section{B. Actuator Faults}

Actuator faults can happen for generator torque, ballast pumps, or ballast valves. This can include "stuck" actuator cases, where controller feedback no longer varies the desired actuator value. Stuck actuators can be modeled by simply eliminating controller feedback, holding the actuator at its previous state.

Additional generator faults include the undesired braking of the generator such that its rotation ceases. Additionally, the electrical load loss will cause the rotor/generator to spin with a near zero shaft torque. For the breaking fault, the braking torque, $\tau_{B}$, is added to the electromechanical torque, $\tau_{E M}$, until the rotor ceases to rotate and then the rotor remains at 0 RPM. For the near zero shaft torque fault, the shaft torque is simply set to zero, and the rotor rotation rate will accelerate until a tip speed ratio is obtained where the hydrodynamic torque is approximately zero.

Likely ballast system failures include valve/tank leakage resulting in the tank being completely filled with water, or a ballast pump being stuck, resulting in a ballast tank being completely emptied of water. For these faults, the rate of change of a fill fraction is set to a constant value until $F_{F}=1$ for water filling the tank and $F_{F}=0$ when the ballast pump is stuck on, pumping all water out of the tank. 


\section{Sensor Faults}

Likely sensors that may subject to faults in the OCT system include water velocity, generator speed, generator power, pitch angle, and IMU. The error in the water velocity sensor can happen due to data loss as well as scale error. Also, both generator speed and generator power sensors suffer from scale error. On the other hand, pitch angle sensor faults occur when the sensor shows a constant pitch angle. Finally, the IMU fault occurs due to an offset on accelerometers or heading measurements.

\section{OCT PREDicted PERformance}

To help quantify buoyancy controlled OCT performance, numerical simulations are conducted for a variety of conditions. OCT operating range is predicted for different flow conditions, system response to both an actuator and rotor faults are evaluated, and system performances in measured open ocean currents are quantified.

\section{A. OCT Operating Range Assessment}

The operating range of OCTs will be important for operating in the most energy dense resources, operating beneath surface waves in storm conditions, and surfacing for maintenance. Therefore, we quantify OCT operating range for two simplistic flow conditions, a homogeneous flow field and a current that linearly decreases with depth (i.e., shear flow), each matched with two operating scenarios. These operating scenarios include maximizing/minimizing depth regardless of OCT pitch angle and maximizing/minimizing depth with an OCT pitch angle near $0^{\circ}$. Hence, the simulation results of the resulting four cases are presented:

Homogeneous flow without pitch control: For this case, numerical simulations were conducted for four different homogeneous flow speeds, 0.5, 1.0, 1.5, 2.0, and $2.5 \mathrm{~m} / \mathrm{s}$, with both ballast tanks filled with water, $F F s=0.0$. Then both ballast tanks were filled with air, $F F s=1.0$, quantify the achievable operating range. Resulting equilibrium states, including altitude (negative depth $-Z$ ), pitch angle $\theta$, and roll angle $\phi$, are presented in Fig. 4 (a) as a function of flow speed. Results show that this OCT can reach the sea surface $(Z \approx 15 \mathrm{~m})$ for flow speeds below $2.2 \mathrm{~m} / \mathrm{s}$, and $Z=38 \mathrm{~m}$ for a flow speed of $2.5 \mathrm{~m} / \mathrm{s}$ when $F F s=1.0$. It is noted that achieved altitudes/depths for flow speeds less than about $2.2 \mathrm{~m} / \mathrm{s}$ result in the turbine operating partially or fully out of the water as the air/sea interface is not modeled. However, these results are relevant to OCTs deployed in deeper water and, therefore, are included. Results also show that maximum depths between $Z=90$ to $329 \mathrm{~m}$ can be achieved for these flow speeds. Results also show OCT roll angles range between $0.03^{\circ}$ to $1.29^{\circ}$, and pitch angles range between $-5.11^{\circ}$ to $9.45^{\circ}$, with the larger pitch angles achieved at deeper depths.

Shear flow without pitch control: In this scenario, numerical simulations were conducted for sea surface flow speeds of $0.5,1.0,1.5,2.0$, and $2.5 \mathrm{~m} / \mathrm{s}$, assuming the flow decreases linearly with depth to a flow speed
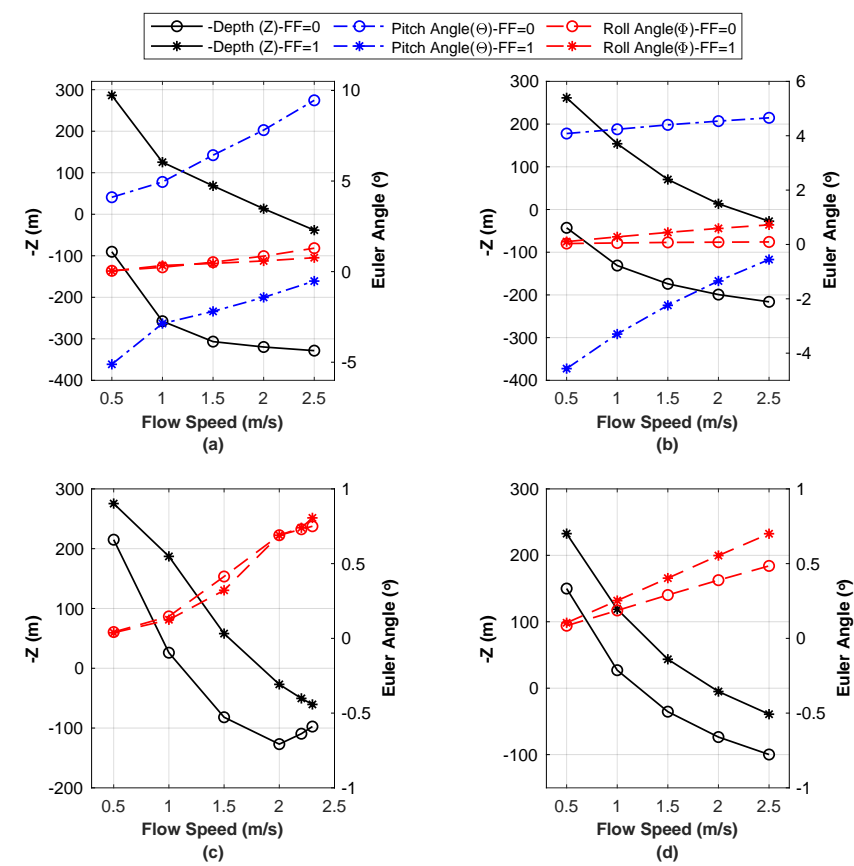

Fig. 4. Operating range assessment for (a) homogeneous flow speeds, (b) shear flow speeds, (c) homogeneous flow speeds ensuring the pitch angle is driven towards zero, and (d) shear flow speed ensuring the pitch angle is driven towards zero.

of $0.0 \mathrm{~m} / \mathrm{s}$ at the seafloor [68], which is located $325 \mathrm{~m}$ below the sea surface. Resulting equilibrium states, including altitude (negative depth $-Z$ ), pitch angle $\theta$, and roll angle $\phi$, are presented in Fig. 4(b) as a function of sea surface flow speed. Results show that this OCT can reach the sea surface $(Z \approx 15 \mathrm{~m})$ for a flow speeds below $2.2 \mathrm{~m} / \mathrm{s}$, and $Z=27 \mathrm{~m}$ for a flow speed of $2.5 \mathrm{~m} / \mathrm{s}$. These results also show that maximum depths between $Z=43$ to $216 \mathrm{~m}$ can be achieved for these flow speeds, more than $100 \mathrm{~m}$ shallower than for a homogeneous flow. For these results, OCT roll angles are between $0.03^{\circ}$ to $0.72^{\circ}$, and pitch angles range between $-4.56^{\circ}$ to $4.66^{\circ}$, with larger pitch angles achieved at deeper depths.

Homogeneous flow with pitch control: This case quantifies the OCT's operating range while the pitch angle, $\theta$, remains near $0^{\circ}$ (i.e., $\pm 0.5^{\circ}$ ), as rotor alignment with the flow increases power production and reduces cyclic loads. Obtained equilibrium states, including $-Z$ and $\phi$ are presented for the homogeneous flow in Fig. 4 (c). The lowest position is found by setting one $F F$ equal to zero (i.e., tank filled with water) and using a controller to change the other $F F$ and drive $\theta$ towards $0^{\circ}$. Similarly, the highest position is found by setting one $F F$ equal to one (i.e., tank filled with air) and using a controller to modify the other $F F$ such that drive $\theta$ towards $0^{\circ}$. Results show that this OCT can only operate beneath the sea surface with zero pitch for flow speeds above $1.2 \mathrm{~m} / \mathrm{s}$, and cannot reach the sea surface for flow speeds above $1.9 \mathrm{~m} / \mathrm{s}$. Additionally, a depth of $50 \mathrm{~m}$ can only be achieved with zero pitch for flow speeds between 1.3 and $2.3 \mathrm{~m} / \mathrm{s}$. Therefore, outside of this range, a finite pitch is necessary for operation at this depth with the current OCT configuration.

Shear flow with pitch control: This case quantifies 

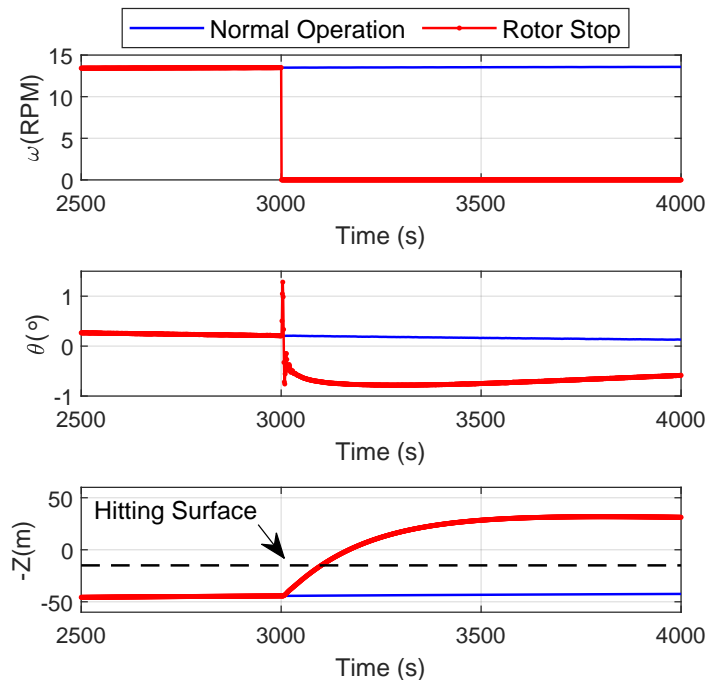

Fig. 5. Time histories of the OCT's equilibrium states, i.e., angular speed $\omega$, pitch angle $\theta$, and vertical position $Z$ before and after rotor stop at Time $=3000$.

the OCT's operating range in the previously described shear flow (see "Shear flow without pitch control" case) where the pitch angle remains near $0^{\circ}$ (see "Homogeneous flow with pitch control" case). Obtained equilibrium states, including $-Z$ and $\phi$ are presented for the homogeneous flow in Fig. 4 (d). Results show this OCT can only operate beneath the sea surface with zero pitch for flow speeds above $1.3 \mathrm{~m} / \mathrm{s}$, and cannot reach the sea surface for flow speeds above $2.1 \mathrm{~m} / \mathrm{s}$. Additionally, a depth of $50 \mathrm{~m}$ can only be achieved with zero pitch for flow speeds between about 1.7 and $2.6 \mathrm{~m} / \mathrm{s}$. Therefore, outside of this range, a finite pitch is necessary for operation at this depth with the current OCT configuration.

\section{B. Actuator Fault Response: Rotor Braking}

The actuator fault scenario of "rotor braking" is presented in this section, which is also a necessary scenario for OCT deployment/retrieval. System response is very dynamic as total system drag decreases by more than $50 \%$. For this analysis, the OCT initially operates at a depth of $50 \mathrm{~m}$ in shear flow with a surface speed of $1.6 \mathrm{~m} / \mathrm{s}$. Rotor rotation, $\omega$, is rapidly stopped at $t=3000 \mathrm{~s}$, and the resulting OCT pitch angle, $\theta$, and vertical position, $-Z$, are presented in Fig. 5, along with the corresponding values if braking is not applied. Presented results show that $\theta$ remains within $1^{\circ}$, as well as changes in both roll, $\phi$, and yaw, $\psi$ (not shown). Moreover, the OCT moves rapidly upwards, hitting the ocean surface in $100 \mathrm{~s}$. Ignoring sea surface effects, these results show a net $80 \mathrm{~m}$ upward OCT displacement, a result relevant to deeper deployment locations. This response can eventually be compensated by adding water to the ballast tanks. However, the ballast process of an OCT will likely occur much more slowly than the response to rotor braking (22 minutes estimated earlier in this paper for a complete ballast). Therefore rotor braking implications should be carefully considered when planning OCT operations.
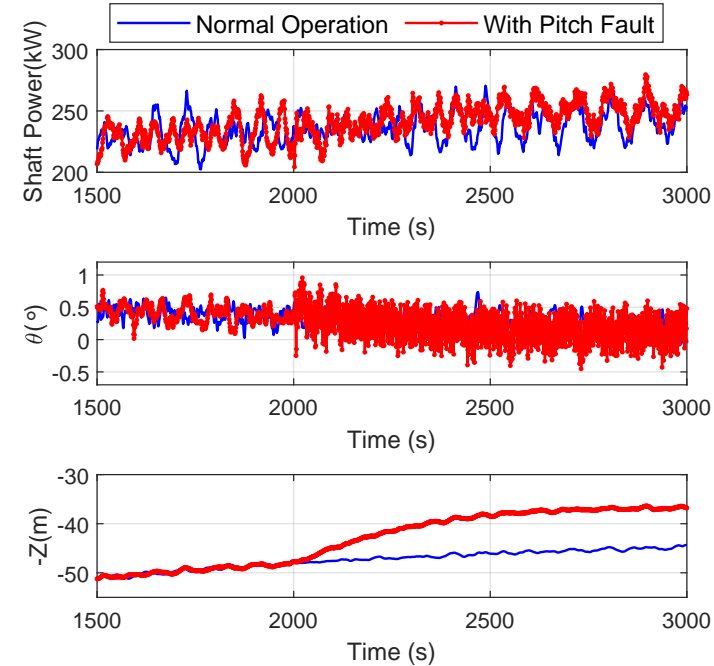

Fig. 6. Time histories of the OCT's equilibrium states, i.e., shaft power, pitch angle $\theta$, and vertical position $Z$ before and after pitch fault at Time $=2000$ at the turbulence intensity of $10 \%$.

\section{Rotor Fault Response: Blade Pitch Fault}

The impacts of blade pitch imbalance faults are highlighted in this section. For this analysis, the OCT initially operates at a depth of $50 \mathrm{~m}$ with a linear shear from a speed of $1.6 \mathrm{~m} / \mathrm{s}$ at the surface to $0.0 \mathrm{~m} / \mathrm{s}$ at the sea floor. A pitch imbalance of $4^{\circ}$ occurs at $t=2000 \mathrm{~s}$ for the "fault" case. Two different turbulence intensities are considered, $0 \%$ to highlight fault signature details and $10 \%$ to highlight how ambient turbulence masks faults signatures. Time histories are shown with and without faults in Fig. 6 for a turbulence intensity of $10 \%$. This figure shows that the shaft power has minimal perceivable deviations in the time domain, while pitch angle deviations are more easily visible. However, these deviations are relatively small with all Euler angles (i.e., pitch angle, roll angle, and yaw angle), remaining within $1^{\circ}$ for all cases. Additionally, the OCT moves $15 \mathrm{~m}$ upward after the blade pitch fault.

The effects of the blade pitch fault are presented in the frequency domain for pitch, $\theta$, and shaft power (Fig. 7). Normalized pitch angle $\theta$ (Fig. 7 (a)) and normalized shaft power (Fig. 7 (b)) spectra for nonturbulent water show spikes at multiples of the rotor angular speed, i.e., $1 \mathrm{P}$ and $2 \mathrm{P}$, and these spikes are even more visible for shaft power. On the other hand, the frequency response of the normalized pitch angle $\theta$ (Fig. 7 (c)) and normalized shaft power (Fig. 7 (d)) spectra are only easily distinguishable at the $1 P$ frequency.

\section{OCT Operating in an Oceanic Environment}

OCT operations in measured oceanic environments are investigated. Simulations are run for a "normal" condition (Fig. 8) and two "hurricane" conditions (Figs. 9 and 10). October 1st, 2017 represents a "normal" condition for this region with a mean flow speed over the simulated time-frame of $1.19 \mathrm{~m} / \mathrm{s}$ at a depth of $75 \mathrm{~m}$. September 11th, 2017 is the date that Hurricane Irma passed through the Florida Keys, resulting in a much higher than normal flow speed in the measurement 


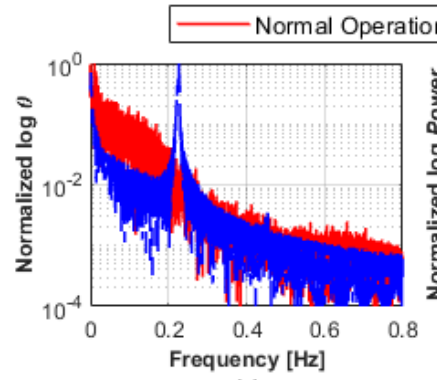

(a)

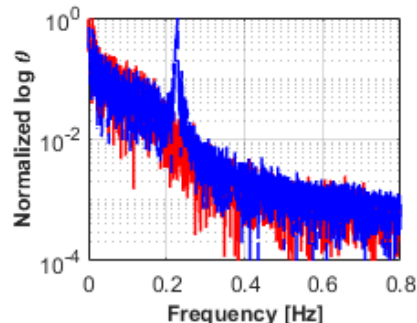

(c)

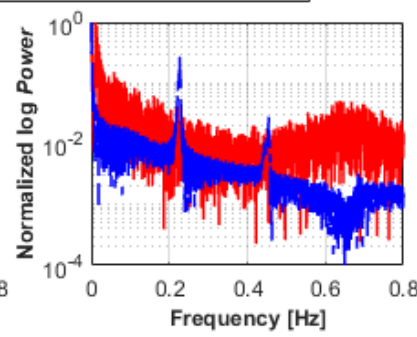

(b)

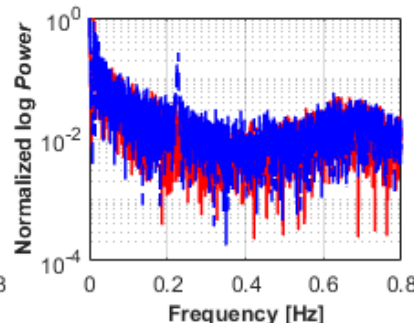

(d)
Fig. 7. Frequency domain of the pitch fault of $4^{\circ}$ for (a) normalized pitch angle $(\theta)$ without turbulence, (b) normalized shaft power without turbulence, (c) normalized pitch angle $(\theta)$ at the turbulence intensity of $10 \%$, and (d) normalized shaft power at the turbulence intensity of $10 \%$.

area [60] (mean flow speed of $2.0873 \mathrm{~m} / \mathrm{s}$ for a depth of $75 \mathrm{~m}$ over the simulated time-frame). September 25th, 2017, had a low current event that was likely associated with Hurricane Irma, as suggested by [60], and/or a counter-clockwise eddy that traveled along the western edge of the Gulf Stream (mean current speed for a depth of $75 \mathrm{~m}$ of $0.87 \mathrm{~m} / \mathrm{s}$ over the simulated time-frame). Wave conditions for these dates are modeled based on the National Oceanic and Atmospheric Administration (NOAA) wave buoy recorded wave heights and direction in the Fort Pierce, Florida [69]. For the October 1st, 2017, the significant wave height and direction are $0.8 \mathrm{~m}$ and $60^{\circ}$, respectively. For the September 11th, 2017, the significant wave height is $5.0 \mathrm{~m}$ and direction is $90^{\circ}$, while on September 25th, 2017, the significant wave height and direction are $2.0 \mathrm{~m}$ and $80^{\circ}$, respectively.

For these simulations, a low gain PI controller sets OCT ballast tank fill levels based on depth error such that a depth near $75 \mathrm{~m}$ is maintained,

$$
F F s=G_{P} *(Z-75)+G_{I} * \int_{0}^{t}(Z-75) d t
$$

where $G_{P}$ is the proportional gain and $G_{I}$ is the integral gain. This also allows for an estimate of the ballast pump power required to maintain depth using equations (2) and (3). Presented results show that the depth remains within $75 \pm 35 \mathrm{~m}$ for both normal and hurricane conditions. Position and power signals in all cases have perturbations at frequencies around 0.0036 $\mathrm{Hz}$ (periods around 4.6 minutes) that are likely related minimally damped position states being excited by low-frequency turbulence perturbations. The stability of moored ocean current turbines is discussed in detail in [58], and these oscillations can be dampened through active control.
The resulting location and power (both harnessed and utilized by ballast pumps) during the "normal" conditions measured on October 1st are presented in Fig. 8 Over the simulated 13 hours of operation flow speeds ranged between $1.06 \mathrm{~m} / \mathrm{s}$ and $1.34 \mathrm{~m} / \mathrm{s}$ at a depth of $75 \mathrm{~m}$, with the flow direction at this depth remaining between $4.29^{\circ}$ and $14.20^{\circ}$. The calculated mean produced power of the OCT is $0.17 \mathrm{MW}$, where the mean ballast power to maintain the depth is $0.02 \mathrm{MW}$ (i.e., $11.76 \%$ of mean produced power). The OCT's east position with respect to the anchor point, $Y$, changes between $41.71 \mathrm{~m}$ and $114.05 \mathrm{~m}$, and its depth, $Z$, remains within $70.86 \mathrm{~m}$ and $93.13 \mathrm{~m}$ below the sea surface. Moreover, the results show that pitch, $\theta$, roll, $\phi$, and yaw, $\psi$, deviations remain within ranges of $2.04^{\circ}$, $1.66^{\circ}$, and $16.80^{\circ}$, respectively (not shown).

For the hurricane condition on September 11, 2017 results are shown in Fig. 9 Over the simulated 14 hours of operation, the flow speeds change within a wider range of $1.85 \mathrm{~m} / \mathrm{s}$ and $2.32 \mathrm{~m} / \mathrm{s}$ at a depth of $75 \mathrm{~m}$, with flow directions between $2.99^{\circ}$ and $17.46^{\circ}$ at this depth. The mean produced power of the OCT increases to $1.06 \mathrm{MW}$ due to higher flow speeds, where the mean ballast power is $0.027 \mathrm{MW}$ (i.e., $2.5 \%$ of mean produced power). It is noted that this produced power is above the "rated" power of $700 \mathrm{~kW}$ mentioned previously for this design. Therefore, either power regulation control such as pitch control or active depth control should be used to keep produced electric power at or below rated power. The OCT moves within $32.62 \mathrm{~m}$ and $167.53 \mathrm{~m}$ in the east position, $Y$, and its depth, $Z$, ranges between $68.33 \mathrm{~m}$ and $110.07 \mathrm{~m}$. Further, the results show that pitch, $\theta$, roll, $\phi$, and yaw, $\psi$, remain within ranges of $4.55^{\circ}, 3.50^{\circ}$, and $19.6^{\circ}$, respectively (not shown).

For the low current case found on September 25th, 2017, results are presented in Fig. 10. Over the simulated 11 hours, flow speeds change within 0.3511 $\mathrm{m} / \mathrm{s}$ and $1.6426 \mathrm{~m} / \mathrm{s}$ at a depth of $75 \mathrm{~m}$, with the flow direction at this depth ranging between $-32.57^{\circ}$ and $46.92^{\circ}$. Mean produced OCT power decreases to 0.039 MW due to lower flow speeds, while the mean ballast power increases to $0.018 \mathrm{MW}$ (i.e., $46.15 \%$ of mean produced power). The OCT moves within a wide range of $-234.30 \mathrm{~m}$ and $316.59 \mathrm{~m}$ in the east direction, $Y$, due to the large changes in flow direction and its depth, $Z$, ranges between $66.87 \mathrm{~m}$ and $85.16 \mathrm{~m}$. It is noted that the OCT hit the sea surface for this case when the current design was used, even when both ballast tanks were completely filled with water. Therefore, the ballast fill levels were allowed to go slightly negative (i.e., the turbine became slightly less buoyant than when both tanks are filled with water) when running this simulation to keep the turbine below the sea surface. Further, the results show that pitch, $\theta$, roll, $\phi$, and yaw, $\psi$, remain within ranges of $1.69^{\circ}, 1.85^{\circ}$, and $74.97^{\circ}$, respectively (not shown).

\section{CONCLUSIONS}

A complete dynamics simulation for a buoyancy controlled OCT system was presented, including a turbine, cable, inflow, actuator (i.e., generator and variable 

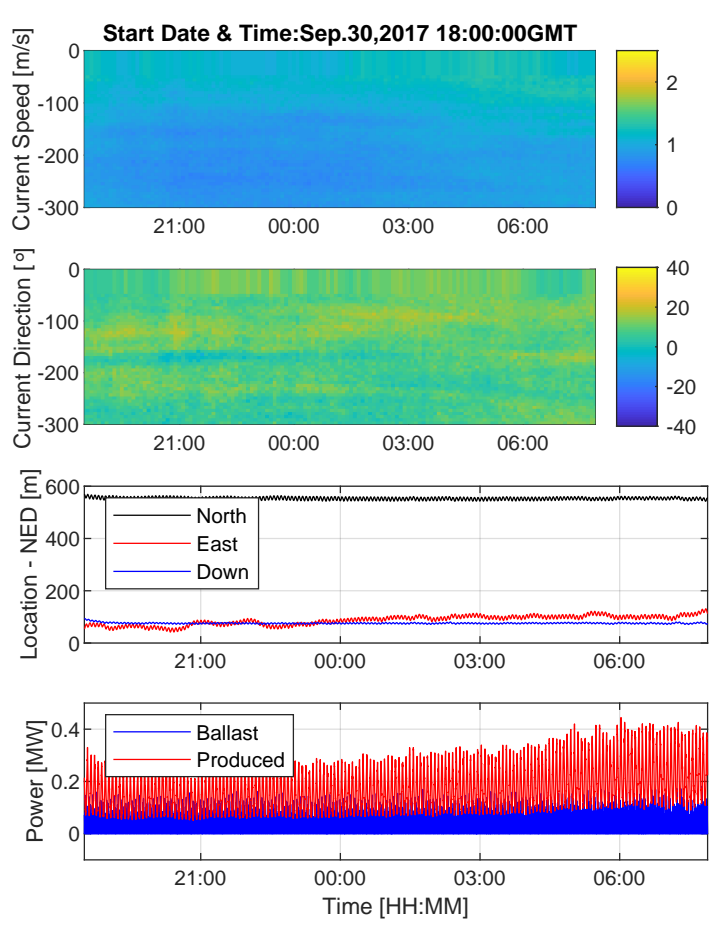

Fig. 8. Normal condition (October 1, 2017): time histories of the OCT's states, i.e., Euler angle, location-NED, and power.
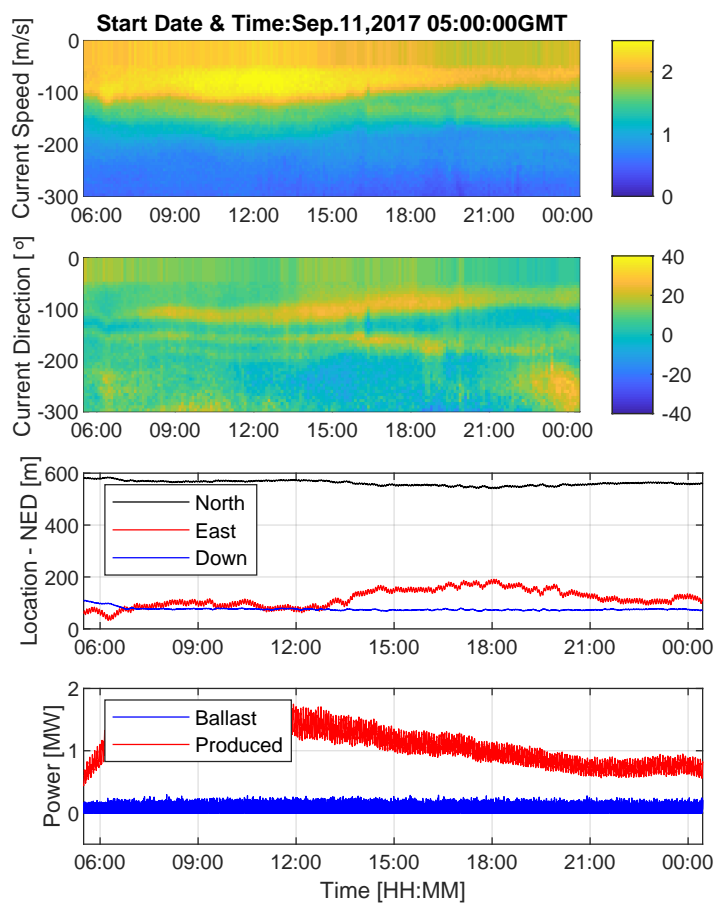

Fig. 9. Hurricane condition (September 11, 2017): time histories of the OCT's states, i.e., Euler angle, location-NED, and power.

buoyancy), and sensor models. Probable OCT faults were integrated into this simulation, including rotor, actuator, and sensor faults. Simulations were run for several different cases, including different simplified flow conditions, both actuator and rotor faults, and system performances in measured open ocean currents. We showed that the OCT can operate between depths of $38 \mathrm{~m}$ to $90 \mathrm{~m}$ for all homogeneous flow speeds between 0.5 and $2.5 \mathrm{~m} / \mathrm{s}$, and depths of $27 \mathrm{~m}$ to $43 \mathrm{~m}$ when the flow decreased linearly with depth from these flow speeds to $0.0 \mathrm{~m} / \mathrm{s}$ at the sea floor.
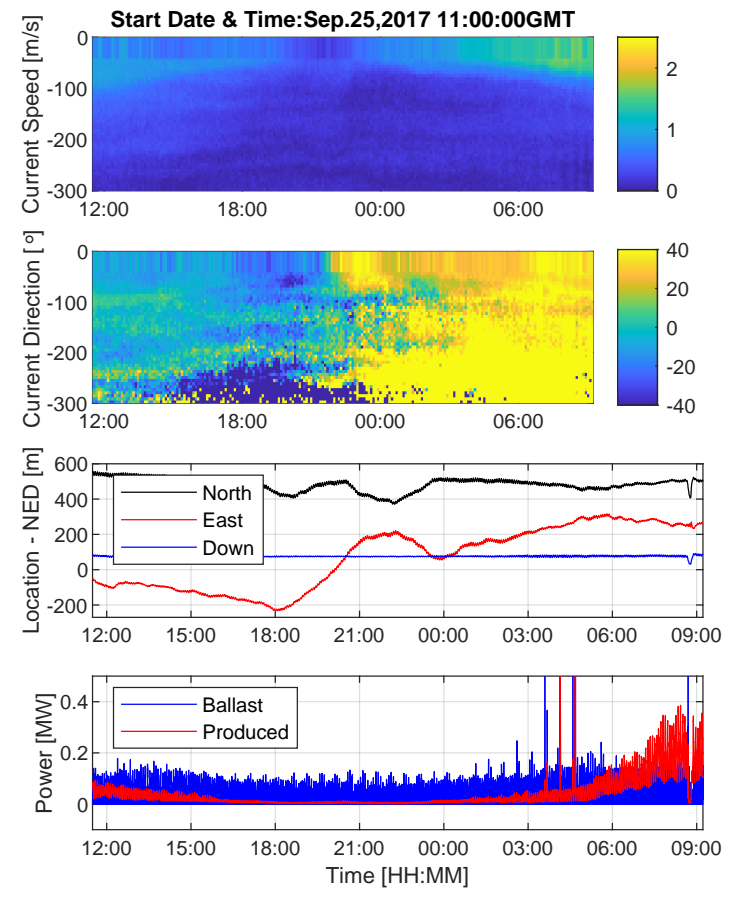

Fig. 10. Hurricane condition (September 25, 2017): time histories of the OCT's states, i.e., Euler angle, location-NED, and power.

Moreover, performance results were presented for both normal and hurricane conditions where the operating depths remained within $75 \mathrm{~m} \pm 35 \mathrm{~m}$ by using a PI controller. Future work will focus on flight and generator control for the buoyancy controlled OCT and the development of a hierarchical control architecture such as a spatiotemporal optimization to maximize harnessed power from the overall OCT system. Control methodologies should also be developed to integrate the harnessed power from the buoyancy controlled OCT into power grids using energy storage and power converters.

\section{ACKNOWLEDGEMENT}

The authors would like the thank the following student researchers who contributed to the development of the sensor and ballast tank models used in this numerical simulation: Michel Dellepere, Juan Rios, Luis Julian Velazquez, and Nathan Witztum.

\section{REFERENCES}

[1] A. v. Jouanne and T. K. A. Brekken, "Ocean and geothermal energy systems," Proceedings of the IEEE, vol. 105, no. 11, pp. 2147-2165, 2017.

[2] P. Jacobson, "Assessment and mapping of the riverine hydrokinetic energy resource in the continental united states," Electric Power Research Insitute (EPRI), 2012.

[3] X. Yang, K. A. Haas, and H. M. Fritz, "Evaluating the potential for energy extraction from turbines in the gulf stream system," Renewable Energy, vol. 72, pp. 12-21, 2014.

[4] J. VanZwieten, A. Duerr, G. Alsenas, and H. Hanson, "Global ocean current energy assessment: an initial look," Proceedings of the 1st Marine Energy Technology Symposium (METS13), 2013.

[5] K. Haas, "Assessment of energy production potential from ocean currents along the united states coastline," Georgia Tech Research Corporation, Tech. Rep., 2013.

[6] D. C. Lund, J. Lynch-Stieglitz, and W. B. Curry, "Gulf stream density structure and transport during the past millennium," Nature, vol. 444, pp. 601-604, 2006.

[7] S. Spring, Russian Marine Expeditionary investigations of The world Ocean. U.S. department of commerce, 2002. 
[8] H. L. Bryden, L. M. Beal, and L. M. Duncan, "Structure and transport of the agulhas current and its temporal variability," Journal of Oceanography, vol. 61, no. 3, pp. 479-492, 2005.

[9] M. C. P. M. Machado, J. H. VanZwieten, and I. Pinos., "A measurement based analyses of the hydrokinetic energy in the gulf stream," Journal of Ocean and Wind Energy, vol. 3, no. 1, pp. 25-30, 2016

[10] J. VanZwieten et al., "Ss marine renewable energy - ocean current turbine mooring considerations," Offshore Technology Conference, 2015.

[11] T. Ueno, S. Nagaya, M. Shimizu, H. Saito, and N. Handa, "Development and demonstration test for floating type ocean current turbine system conducted in kuroshio current," in 2018 OCEANS-MTS/IEEE Kobe Techno-Oceans (OTO). IEEE, 2018, pp. $1-6$.

[12] D. Coiro, G. Troise, F. Scherillo, A. De Marco, G. Calise, and N. Bizzarrini, "Development, deployment and experimental test on the novel tethered system gem for tidal current energy exploitation," Renewable energy, vol. 114, pp. 323-336, 2017.

[13] Q. Abu-al rubb, Khalil (Doha, "Water turbine with variable buoyancy," Patent 20160160835 , June, 2016. [Online]. Available: http://www.freepatentsonline.com/y2016/0160835.html

[14] F.-L. Chiu, S.-A. Lai, C.-F. Lee, Y.-A. Tzeng, and C.-Y. Hsin, "Design and analysis of the floating kuroshio turbine blades," Journal of Taiwan Society of Naval Architects and Marine Engineers, vol. 37, no. 2, pp. 73-81, 2018.

[15] J.-T. Wu, J.-H. Chen, C.-Y. Hsin, and F.-C. Chiu, "Dynamics of the fkt system with different mooring lines," Polish Maritime Research, 2019.

[16] A. Fleming, "Aquantis c-plane ocean current turbine project," Dehlsen Associates, LLC, Santa Barbara, CA (United States), Tech. Rep., 2015.

[17] Minesto - power from tidal and ocean currents. [Online]. Available: http.wwww.minesto.com

[18] V. S. Neary, M. Previsic, R. A. Jepsen, M. J. Lawson, Y.-H. Yu, A. E. Copping, A. A. Fontaine, K. C. Hallett, and D. K. Murray, "Methodology for design and economic analysis of marine energy conversion (mec) technologies," Sandia National Laboratories, Tech. Rep., 2014.

[19] S. Tandon, S. Divi, M. Muglia, C. Vermillion, and A. Mazzoleni, "Modeling and dynamic analysis of a mobile underwater turbine system for harvesting marine hydrokinetic energy," Ocean Engineering, vol. 187, p. 106069, 2019.

[20] V. S. Neary, M. Lawson, M. Previsic, A. Copping, K. C. Hallett, A. LaBonte, J. Rieks, and D. Murray, "Methodology for design and economic analysis of marine energy conversion (mec) technologies." Sandia National Lab.(SNL-NM), Albuquerque, NM (United States), Tech. Rep., 2014.

[21] A. Baheri, P. Ramaprabhu, and C. Vermillion, "Iterative 3d layout optimization and parametric trade study for a reconfigurable ocean current turbine array using bayesian optimization," Renewable energy, vol. 127, pp. 1052-1063, 2018.

[22] A. Tidal, "Environmental appraisal (ea) for the argyll tidal demonstrator project," Tech. Rep., 2013.

[23] K. Shirasawa, K. Tokunaga, H. Iwashita, and T. Shintake, "Experimental verification of a floating ocean-current turbine with a single rotor for use in kuroshio currents," Renewable Energy, vol. 91, pp. 189-195, 2016.

[24] B. Davis, J. Farrell, D. Swan, K. Jeffers et al., "Generation of electrical power from the florida current of the gulf stream," in Offshore Technology Conference. Offshore Technology Conference, 1986.

[25] "Ocean energy technology: The davis hydro turbine," Refocus, vol. 2, no. 2, pp. 44-47, 2001.

[26] J. VanZwieten, F. Driscoll, A. Leonessa, and G. Deane, “Design of a prototype ocean current turbine-part ii: flight control system," Ocean engineering, vol. 33, no. 11-12, pp. 1522-1551, 2006.

[27] H. Swales, D. Coackley, S. Gupta, S. Way et al., "Stability and loads validation of an ocean current turbine," 2014.

[28] W. D. Bolin, "Systems and methods for transportation and maintenance of a water current power generation system," Jun. 22 2017, uS Patent App. 15/446,207.

[29] "Ihi demonstrated the world's largest ocean current turbine for the first time in the world," IHI Engineering review, vol. 52, no. 1, pp. 6-9, 2019.

[30] D. Iaconangelo. Ocean electricity takes 'big step' with baseload project. [Online]. Available: https://www.eenews.net/stories / 1063312473

[31] J.-F. Tsai, Y.-X. Zeng, and F.-C. Chiu, "Study on the hydrodynamic performance of a floating kuroshio current turbine,"
Proceedings of the 3rd World Congress on Civil, Structural, and Environmental Engineering (CSEE'18), 2018.

[32] K. Shirasawa, J. Minami, and T. Shintake, "Scale-model experiments for the surface wave influence on a submerged floating ocean-current turbine," Energies, vol. 10, no. 5, p. 702, 2017.

[33] D. Coiro, D. Iannuzzi, M. Coppola, L. Di Noia, G. Troise, N. Bizzarrini, and G. Lazzerini, "Coupling fixed pitch rotor design to pmg de-fluxing control for gemstar marine current turbine," in 2019 International Conference on Clean Electrical Power (ICCEP). IEEE, 2019, pp. 680-689.

[34] J. G. P. DehlsenJames, B. DehlsenGeoffrey, and F. Deane, "Method of controlling operating depth of an electricitygenerating device having a tethered water current-driven turbine," Patent US6091161A, 2000. [Online]. Available: https://patents.google.com/patent/US6091161A/en\#title

[35] "Southeast National Marine Renewable Energy Center," http: //snmrec.fau.edu/ accessed: 2020-05-30.

[36] K. Sakata, T. Gonoji, and K. Takagi, "A motion of twin type ocean current turbines in realistic situations," 2012 Oceans Yeosu, 2012.

[37] K. Takagi, Y. Suyama, and K. Kagaya, "An attempt to control the motion of floating current turbine by the pitch control," OCEANS'11 MTS/IEEE KONA, 2011.

[38] K. Takagi, "Motion analysis of floating type current turbines," in International Conference on Offshore Mechanics and Arctic Engineering, vol. 44946. American Society of Mechanical Engineers, 2012, pp. 189-195.

[39] K. Takeda, K. Sakata, and K. Takagi, "Motion simulation of a twin-type ocean current turbine," Journal of the Japan Society of Naval Architects and Ocean Engineers, vol. 18, 2013.

[40] T. Gonoji and K. Takagi, "Motion of a twin-rotor ocean current turbine in transient state," Journal of the Japan Society of Naval Architects and Ocean Engineers, vol. 20, 2014.

[41] T. Gonoji, K. Takagi, and K. Takeda, "Motion of twin type ocean current turbine at the time of startup and accident," in 2013 OCEANS-San Diego. IEEE, 2013, pp. 1-6.

[42] J. H. VanZwieten, N. Vanrietvelde, and B. L. Hacker, "Numerical Simulation of an Experimental Ocean Current Turbine," IEEE Journal of Oceanic Engineering, vol. 38, no. 1, pp. 131-143, Jan. 2013.

[43] P. Pyakurel, J. H. VanZwieten, C. Sultan, M. Dhanak, and N. I. Xiros, "Numerical simulation and dynamical response of a moored hydrokinetic turbine operating in the wake of an upstream turbine for control design," Renewable Energy, vol. 114, pp. 1134-1145, 2017.

[44] J. H. VanZwieten, P. Pyakurel, T. Ngo, C. Sultan, and N. I. Xiros, "An assessment of using variable blade pitch for moored ocean current turbine flight control," International journal of marine energy, vol. 13, pp. 16-26, 2016.

[45] Y. Tang, J. VanZwieten, B. Dunlap, D. Wilson, C. Sultan, and N. Xiros, "In-stream hydrokinetic turbine fault detection and fault tolerant control-a benchmark model," 2019 American Control Conference (ACC), pp. 4442-4447, 2019.

[46] D. Wilson, S. Passmore, Y. Tang, and J. Vanzwieten, "Bidirectional long short-term memory networks for rapid fault detection in marine hydrokinetic turbines," 2018 17th IEEE International Conference on Machine Learning and Applications (ICMLA), pp. 495-500, 2018.

[47] M. Zhang, T. Wang, T. Tang, M. Benbouzid, and D. Diallo, “An imbalance fault detection method based on data normalization and emd for marine current turbines," ISA transactions, vol. 68, pp. 302-312, 2017.

[48] B. Freeman, Y. Tang, and J. VanZwieten, "Marine hydrokinetic turbine blade fault signature analysis using continuous wavelet transform," 2019 IEEE Power \& Energy Society General Meeting (PESGM), pp. 1-5, 2019.

[49] B. Freeman, Y. Tang, Y. Huang, and J. VanZwieten, "Rotor blade imbalance fault detection for variable-speed marine current turbines via generator power signal analysis," Ocean Engineering, vol. 223, p. 108666, 2021.

[50] P. Wen, T. Wang, B. Xin, T. Tang, and Y. Wang, "Blade imbalanced fault diagnosis for marine current turbine based on sparse autoencoder and softmax regression," in The 33rd Youth Academic Annual Conference (YAC). IEEE, 2018, pp. 246-251.

[51] Y. Huang, Y. Tang, J. VanZwieten, J. Liu, and X. Xiao, "An adversarial learning approach for machine prognostic health management," 2019 International Conference on High Performance Big Data and Intelligent Systems (HPBDEIS), pp. 163-168, 2019.

[52] Y. Huang, Y. Tang, J. VanZwieten, G. Jiang, and T. Ding, "Remaining useful life estimation of hydrokinetic turbine blades using power signal," 2019 IEEE Power E Energy Society General Meeting (PESGM), pp. 1-5, 2019. 
[53] F. R. Driscoll, G. M. Alsenas, P. P. Beaujean, S. Ravenna, J. Raveling, E. Busold, and C. Slezycki, "A $20 \mathrm{KW}$ open ocean current test turbine," in OCEANS 2008, Sep. 2008.

[54] M. Borghi, F. Kolawole, S. Gangadharan, W. Engblom, J. VanZwieten, G. Alsenas, W. Baxley, and S. Ravenna, “Design, fabrication and installation of a hydrodynamic rotor for a smallscale experimental ocean current turbine," in 2012 Proceedings of IEEE Southeastcon. IEEE, 2012.

[55] M. U. Rentschler, F. Adam, and P. Chainho, "Design optimization of dynamic inter-array cable systems for floating offshore wind turbines," Renewable and Sustainable Energy Reviews, vol. 111, pp. 622-635, 2019.

[56] M. Drela, "Xfoil: An analysis and design system for low reynolds number airfoils," in Low Reynolds number aerodynamics. Springer, 1989, pp. 1-12.

[57] C. Hansen and N. Codes, "Airfoilprep," NWTC Design Codes, Available: http://wind. nrel. gov/designcodes/preprocessors/airfoilprep/Last modified, 2010

[58] T. D. Ngo, C. Sultan, J. H. VanZwieten, and N. I. Xiros, “Constrained control of moored ocean current turbines with cyclic blade pitch variations," IEEE Journal of Oceanic Engineering, pp. 1-17, 2020.

[59] P. Pyakurel, J. H. VanZwieten, M. Dhanak, and N. I. Xiros, "Numerical modeling of turbulence and its effect on ocean current turbines," International journal of marine energy, vol. 17, pp. 84-97, 2017.

[60] W. E. Baxley, J. VanZweiten, and N. Small, "Measuring the effects of hurricanes on major ocean currents and implications for ocean energy devices," in 2019 IEEE/OES Twelfth Current, Waves and Turbulence Measurement (CWTM), 2019, pp. 1-6.

[61] S. Harding, L. Kilcher, and J. Thomson, "Turbulence Measurements from Compliant Moorings. Part I: Motion Characterization," Journal of Atmospheric and Oceanic Technology, vol. 34, no. 6, pp. 1235-1247, 06 2017. [Online]. Available: https://doi.org/10.1175/JTECH-D-16-0189.1

[62] Y. Tang, Y. Zhang, A. Hasankhani, and J. VanZwieten, "Adaptive super-twisting sliding mode control for ocean current turbine-driven permanent magnet synchronous generator," in 2020 American Control Conference (ACC). IEEE, 2020, pp. 211217.

[63] A. Hasankhani, Y. Tang, J. VanZwieten, and C. Sultan, “Comparison of deep reinforcement learning and model predictive control for real-time depth optimization of a lifting surface controlled ocean current turbine," in 2021 IEEE Conference on Control Technology and Applications (CCTA). IEEE, Accepted.

[64] The fleet type submarine online submarine trim and drain systems (chapter 2). [Online]. Available: https://maritime.org/ doc/fleetsub/trim/chap2.htm

[65] M. T. Young, Design and analysis of an ocean current turbine performance assessment system. Florida Atlantic University, 2012.

[66] M. D. Reder, E. Gonzalez, and J. J. Melero, "Wind turbine failures - tackling current problems in failure data analysis," Journal of Physics: Conference Series, vol. 753, p. 072027, 2016.

[67] J.-S. Chou, C.-K. Chiu, I.-K. Huang, and K.-N. Chi, "Failure analysis of wind turbine blade under critical wind loads"," Engineering Failure Analysis, vol. 27, pp. 99-118, 2013.

[68] J. VanZwieten et al., "Ss marine renewable energy-ocean current turbine mooring considerations," in Offshore Technology Conference. Offshore Technology Conference, 2015.

[69] Monitoring and prediction of waves and shoreline changes. [Online]. Available: http://cdip.ucsd.edu/m/products $/$ ?stn= 134p1\&param=waveHs 